\title{
Simulation of Water Vapor Condensation in a Partly Closed Structure: The Influence of the External Conditions of Temperature and Humidity
}

\author{
Jean Batina ${ }^{1}$ and René Peyrous ${ }^{2}$ \\ ${ }^{1}$ Laboratoire des Sciences de l'Ingénieur Appliquées à la Mécanique et à l'Electricité (SIAME), Université de Pau et des Pays de l’Adour, \\ BP 1155, 64013 Pau, France \\ ${ }^{2}$ Laboratoire d'Electronique des Gaz et des Plasmas, Université de Pau et des Pays de l'Adour, 64000 Pau, France
}

Correspondence should be addressed to Jean Batina; jean.batina@univ-pau.fr

Received 7 May 2013; Accepted 6 June 2013

Academic Editors: H. A. Flocas and A. Luhar

Copyright (C) 2013 J. Batina and R. Peyrous. This is an open access article distributed under the Creative Commons Attribution License, which permits unrestricted use, distribution, and reproduction in any medium, provided the original work is properly cited.

Our aim is to determine the more significant parameters acting on the water vapor condensation in a partly closed structure, submitted to external constraints (temperature and humidity) which induce convective movements and thermal variations inside. These constraints locally lead to condensation of the water vapor, initially contained in the air of the volume and/or on the walls. The inside bottom wall is remained dry. Condensed water quantities depend on: (1) dimensions of the structure, (2) the air renewing and its hygrometry, and (3) the phase between thermal and hydrometric conditions. Peculiar conditions are needed to obtain a maximum of condensation.

\section{Introduction}

A lot of experimental and fundamental works have shown the possibility to condense the water vapor contained in ambient air with a view to recover it. We can mention the work of Nikolayev et al. [1] who highlighted the importance to study the basic physical phenomena in the formation of dew and the possibility to improve its recovering. In the same way, Muselli et al. [2] studied a dew water collector for potable water in Ajaccio. In their investigations concerning the mechanism of soil water vapor adsorption in arid regions, Beysens et al. [3] concluded that "there are areas in which, during the dry season, the dominant process is vapor adsorption, and dew formation is a rare occurrence." This study and several others on the same subject shows the importance to characterize the main parameters intervening in the formation of water vapor condensation, particularly in arid regions. All these scientific works demonstrate that successes concerning water recovering possibilities by the mean of water vapor contained in ambient air remain limited and the subject causes scientific debates. The numerical simulation, more and more current in engineering sciences, is not very useful to describe, understand, and explain this complex process in which heat and mass transfer and thermodynamic of the mixture occur in a strong interactive manner at the same time, Gandhidasan and Abualhamayel [4], Beysens et al. [5], Caltagirone and Breil [6].

The aim of this study is to determine the more significant parameters acting on the conditions of the water vapor condensation present in air, inside a closed or partly closed structure (Batina et al. [7], and Batina et al. [8]). An illustration of such phenomena can be found in the case of the Arles-sur-Tech (France) sarcophagus (nonwatertight) Beysens et al. [9], Perard and Leborgne [10], the marble walls dimensions of which result in an about $0.33 \mathrm{~m}^{3}$ internal volume. This structure is submitted to external atmospheric conditions (temperature and humidity) which generate convective movements and thermal variations inside this space. These ones are then able to generate locally, in the structure or/and on the walls, the condensation of the water vapor of the air initially contained in the volume or renewed by introducing through an orifice. The approach of the external 


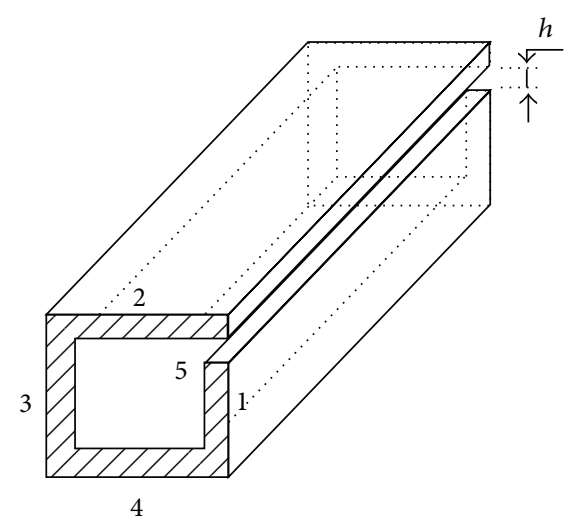

FIGURE 1: Transverse section showing the boundary conditions-(1) and (2): walls submitted to periodic external constraints; (3) and (4): adiabatic walls; (5): orifice (renewing internal air).

atmospheric conditions (temperature and hygrometry) was, in a first time and in a simplified way, made by representing the daily thermal variations $(T)$ by a sinusoidal function and the relative hydrometric variations $(\mathrm{RH})$ by crenels with a same period. These two parameters are linked by a temporal phase $\varphi(T / R H)$ which is varied by steps of $3 \mathrm{~h}$, from 0 to $24 \mathrm{~h}$. The thermal and hydrometric evolutions and the resulting condensed water quantities, inside the considered volume, are represented, for a transverse section, at various moments of the day as a function of the phase $\varphi(T / \mathrm{RH})$ for $\varphi=0 \mathrm{~h}$ and $\varphi=12 \mathrm{~h}$. Taking into account the extent of the inquiry field, the numerical simulation permits to consider a lot of variable parameters which can be modified. Our study is essentially founded on the Arles-sur-Tech sarcophagus case for which we have some experimental results running on some months. In a first time, despite the importance of their role, the volume of the structure, the dimension of the orifice, and the nature of the walls material (marble) remain unchanged. The study, as a function of $\varphi$, on the dynamical and thermal behaviour and on the condensation effects, shows the existence of an optimum of condensation linked with this parameter $\varphi$.

\section{Modelisation}

In the parallelepipedic structure of internal dimensions: $0.47 \mathrm{~m} \times 0.40 \mathrm{~m} \times 1.76 \mathrm{~m}$, we will consider only the transverse section $(0.47 \mathrm{~m} \times 0.40 \mathrm{~m})$, named "width section" (Figure 1), in which the convective movements take place. The marble walls, of $0.1 \mathrm{~m}$ thick, are assumed as watertight and smooth. The frontal side 1 and the top side 2 (Figure 1) are submitted to the external atmospheric conditions (temperature and humidity) varying periodically in time, when all the other sides $(3,4$, etc.) are considered as adiabatic (null thermal flux conditions). The orifice 5, of which the thickness $h$ can be varied from $0.02 \mathrm{~m}$ up to $0.30 \mathrm{~m}$, and from which the inside air can be renewed only by the outside-inside thermal gradient, is situated on the upper and right part of the width section, on the side of the walls submitted to the constraints (Figure 1). The external air is without initial speed on the level of the orifice, at the initial temperature of $15^{\circ} \mathrm{C}$ with a relative hygrometry in a $60 \%$ to $90 \%$ range at $6 \mathrm{~h}$ a.m. (reference values). The humid air contained in the structure is consequently submitted to a natural convective phenomenon and its renewing is only obtained by the mean of the orifice.

Atmospheric pressure, relative humidity, and temperatures involved are issued from mean values coming from the experimental results obtained by Perard and Leborgne [10]. Moreover, the temperature variations are sufficiently reduced to justify the Boussinesq approximation. In these conditions, the equations system to solve contains the movement quantity and energy conservation and continuity (Navier-Stokes). Their classical vectorial forms are the following

$$
\begin{gathered}
\rho\left[\frac{\partial \vec{V}}{\partial t}+(\vec{V} \cdot \vec{\nabla}) \vec{V}\right]=-\vec{\nabla} p+\mu \vec{\nabla} \cdot\left(\nabla \vec{V}+\nabla^{t} \vec{V}\right)+\rho \vec{g} \\
\vec{\nabla} \cdot \vec{V}=0 \\
\rho c_{p}\left[\frac{\partial T}{\partial t}+\vec{V} \cdot \vec{\nabla} T\right]=\lambda \Delta T+S .
\end{gathered}
$$

To these dynamic and thermal equations, we must add the transport equation of the water vapor given by:

$$
\frac{\partial c}{\partial t}+\vec{V} \cdot \vec{\nabla} c=\vec{\nabla}(D \vec{\nabla} c)+S^{\prime}
$$

where $S$ and $S^{\prime}$, respectively, represent the source terms (heat for (3), and mass for (4)), coming from the external air, and representing the balance between evaporation and condensation of the water vapor contained in air.

The state equations of the humid air, given by the Mollier diagram, enable to relate dry temperature and relative humidity with the other characteristic variables of the air: more particularly absolute (or specific) humidity and dewpoint temperature.

Starting from a defined configuration, we vary in time the thermal and hydrometric conditions of the external air (boundary conditions on the constrained walls), with a $24 \mathrm{~h}$ period: sinusoidal variations of the temperature $(T=15 \pm$ $5^{\circ} \mathrm{C}$ ), $15^{\circ} \mathrm{C}$ at $6 \mathrm{~h}$ in the morning, maximum at $12 \mathrm{~h}$ (noon), and minimum at $24 \mathrm{~h}$ (midnight); crenelled periodical variations for the relative hygrometry $(\mathrm{RH}=60 \%$ during $10 \mathrm{~h}$ from $7 \mathrm{~h}$ a.m. up to $5 \mathrm{~h}$ p.m., centered at noon; $\mathrm{RH}=90 \%$ during $14 \mathrm{~h}$ from $5 \mathrm{~h}$ p.m. up to $7 \mathrm{~h}$ a.m. the next morning, centered at midnight).

Our initial phase is $\varphi=0 \mathrm{~h}$ (Figure 2). Though nonrealistic, these crenelled variations of $\mathrm{RH}$ have permitted to check the stability of the numerical model. At the moment $t=0(6 \mathrm{~h}$ in the morning), we assume that the fluid (wet air), inside the considered volume, is in a steady state with uniform mean relative humidity and temperature. The thermal constraint is applied over two adjacent external sides, the other sides remaining adiabatic.

The modelisation of the process is in two dimensions, according to a transverse section, and the mesh grid is structured, strongly refined in the orifice wake and in the vicinity of the walls.

The grid includes $5940(66 \times 90)$ meshes in the totality. 


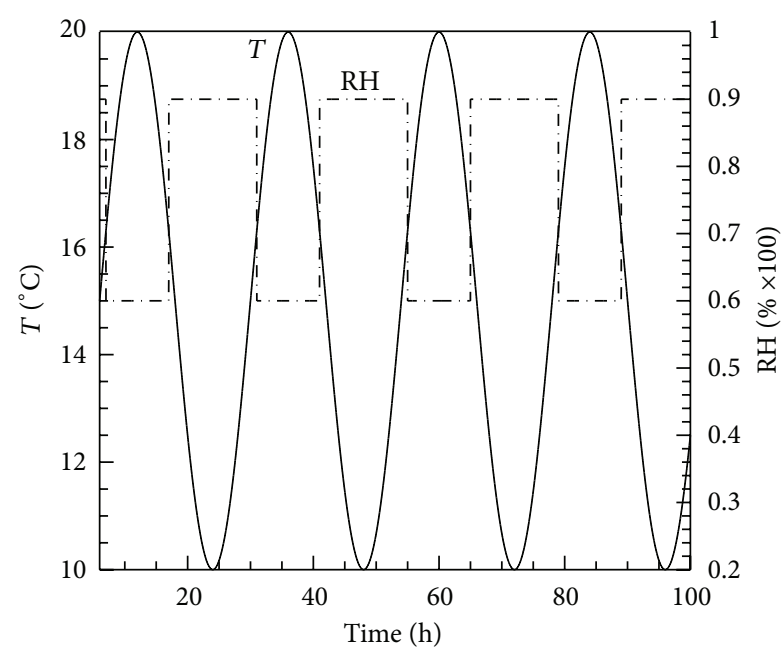

FIgURE 2: Temperature $(T)$ and relative humidity (RH) temporal evolutions of the external air (boundary conditions on the constrained walls): phase $\varphi=0 \mathrm{~h}$.

Equations are solved according to the finite volumes method particularly developed by Caltagirone and Breil [6], using the Gear time scheme of order 2, the time-step of which is fixed at $5 \mathrm{~s}$.

Starting from these stable initial conditions, we show that the considered system reaches a steady state regime (no more variations at the same time from day to day) after 3 days (see Figure 6).

This study on the dynamical behaviour as well as the condensation effects, as a function of $\varphi$ and of the orifice thickness $h$, shows the existence of an optimum of condensation linked with these parameters.

We will present our results by firstly taking into consideration the simplified hypothesis of a remaining dry inside bottom wall.

In a future paper, we will present the results obtained with a wet bottom wall and a small water layer remaining levelconstant in time. This second hypothesis will permit to work with constant inner volume of air.

\section{Results and Discussion}

We have chosen to show only the more significant results in a fixed configuration: width section, $0.08 \mathrm{~m}$ orifice, for two phases $(\varphi=0 \mathrm{~h}$ and $\varphi=12 \mathrm{~h})$ at various moments.

3.1. Phase $\varphi=0 \mathrm{~h}$. In Figures 3(a) and 3(b) we can see the main role played by the thermal gradient between the outside and the inside of the structure and, in the same way, the role of the thermal inertia of the walls on the fluid circulation inside the studied volume: mainly clockwise circulation in the upper part at about $0 \mathrm{~h}$ (midnight), double cell circulation at $6 \mathrm{~h}(\mathrm{am})$, and mainly anticlock wise at $12 \mathrm{~h}$ (noon) and $18 \mathrm{~h}(6 \mathrm{~h} \mathrm{pm})$. The more important velocities are about the size order of $5.10-2 \mathrm{~m} / \mathrm{s}$. We can note a "buffer effect" (very small speeds of exchanges) at the structure entrance at $0 \mathrm{~h}$ (midnight) and more important at $18 \mathrm{~h}$ ( $6 \mathrm{~h}$ p.m.). At $6 \mathrm{~h}$ (a.m.) and at noon, the circulations at the structure entrance are very looking like (coming into the structure from the top, going out by the down).

This circulation will act on the isothermal and isohumidity distributions inside the structure. The behaviour of the bi-dimensional section of the local heat-fields is represented Figure 4 .

Isotherms (difference value from $15^{\circ} \mathrm{C}$ ) show a natural convective activity, fairly important, indicated by temperature difference values of about $5^{\circ} \mathrm{C}$ in some occurrences $(0 \mathrm{~h})$, able to produce condensation phenomena or drying effects inside the structure.

In Figure 4, at midnight $(0 \mathrm{~h})$ and at $6 \mathrm{pm}(18 \mathrm{~h})$, the numbered isotherms 1 represent the external air temperature (gap value compared with $15^{\circ} \mathrm{C}$ : $\delta T=0^{\circ} \mathrm{C}$ initial, see Figure $2 ;-5^{\circ} \mathrm{C}$ at midnight $(0 \mathrm{~h})$ and $0^{\circ} \mathrm{C}$ at $6 \mathrm{pm}(18 \mathrm{~h})$. In the same Figure 4, at $6 \mathrm{a} . \mathrm{m}$. and at noon $(12 \mathrm{~h})$ the isotherms, respectively, numbered 10 and 15 play the same role: $0^{\circ} \mathrm{C}$ at $6 \mathrm{am}$ and $5^{\circ} \mathrm{C}$ at noon $(12 \mathrm{~h})$. The used temperature scales are function of the obtained thermal variations for the considered moment.

It can be noted that the upper temperature variation compared with the external one is obtained at noon $(12 \mathrm{~h})$ $\left(\delta T=-3^{\circ} \mathrm{C}\right)$, inside the structure, all along the inner walls.

About the relative iso humidity (Figure 5), we point out a condensation possibility relatively high in the vicinity of the walls under constraints at $0 \mathrm{~h}$ and $6 \mathrm{~h}(\mathrm{am})$ when, at $6 \mathrm{pm}$ $(18 \mathrm{~h})$, the imposed external hygrometry is of $90 \%$; there is not a possibility of condensation due to the too low negative temperature gap.

The best possibilities of condensation will be between midnight $(0 \mathrm{~h})$ and $6 \mathrm{~h}(\mathrm{am})$, when $\delta T$ is the more important. Drying effects can be noted in some zones, particularly at noon $(12 \mathrm{~h})$, but in this case the external humidity is of only $60 \%$. At $18 \mathrm{~h}(6 \mathrm{pm})$, the imposed external hygrometry is $90 \%$, but the inside mean temperature gap $\delta T$ is always positive.

The hygrometry dispatch outside of these zones remains relatively homogeneous. Actually, the water vapor diffusion phenomenon inside the structure has a more important kinetic than the convection one and participates more actively to the humidity homogenisation.

As for the isothermal curves, the relative hygrometry variations scales depend on the considered moment. The following isohumidity curves (Figure 5), associated with the previous isothermal figures (Figure 4), permit a local view of the dynamical, thermal, and hydrometric behaviour at each moment of the studied case.

Nevertheless, a global view of this behaviour (by numerical integration of the variables in space) is better illustrated by the evaporation/condensation phenomena taking place inside the structure. This behaviour points out the phases due to the presence of the marble walls which have higher thermal inertia than the inner air. Starting from the synchronous boundary conditions $\varphi=0 \mathrm{~h}$ (Figure 2), we can see in Figure 6(a) that mean temperature and hygrometry values follow a similar behaviour to the ones outside the structure with $\mathrm{RH}$ upper values higher than $90 \%$ and lower than $60 \%$.

We can notice a dephasing of about 2 hours between temperature and relative hygrometry due to the walls effect. 

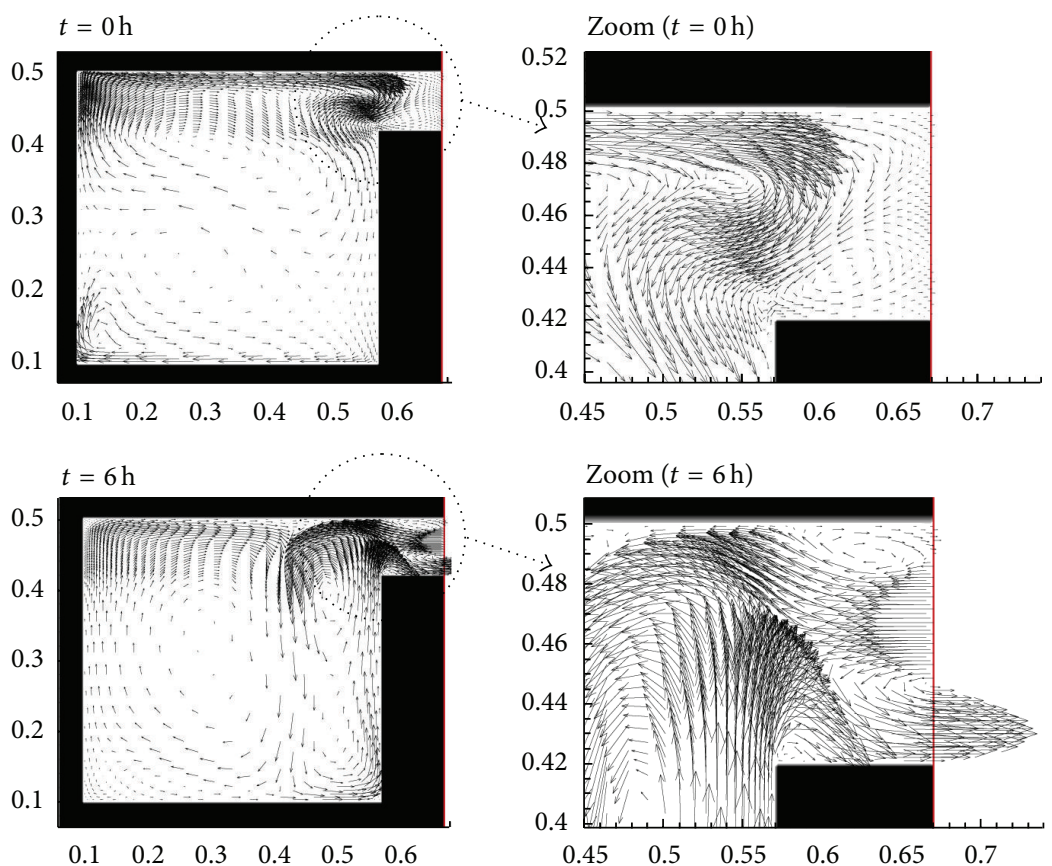

(a)
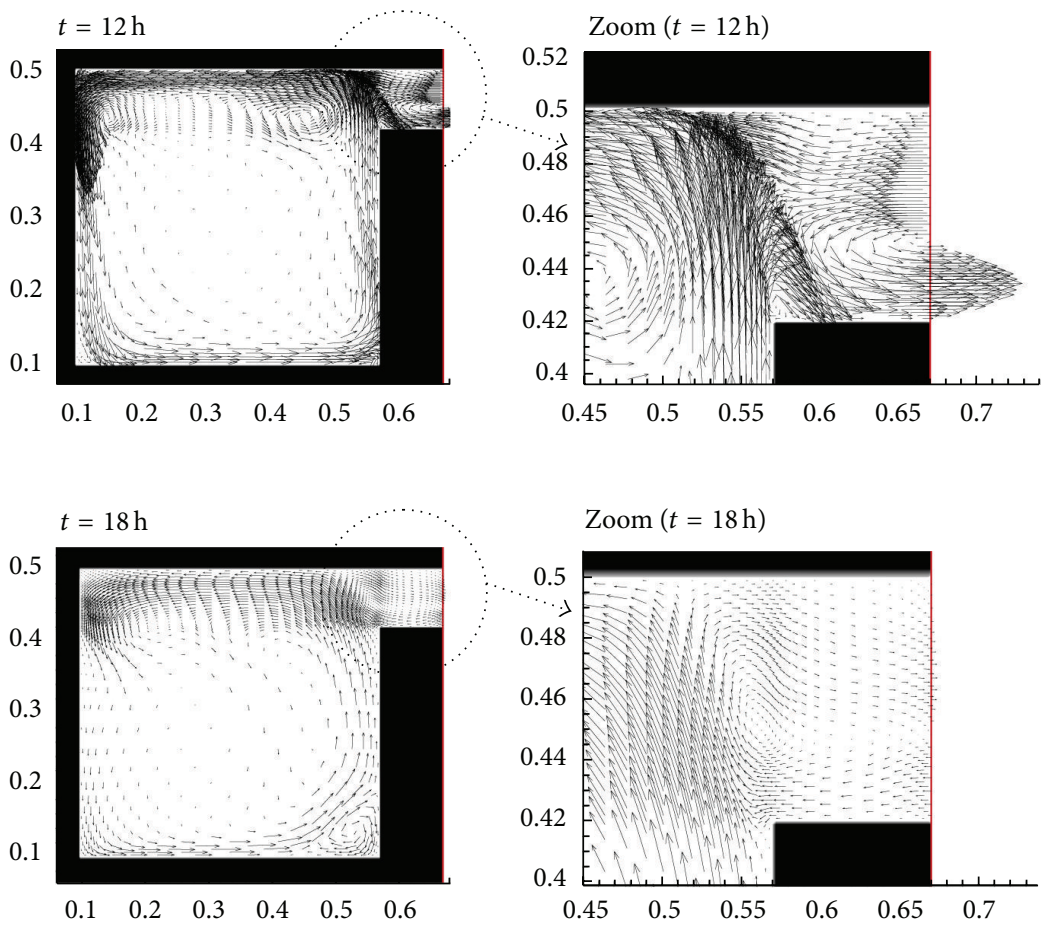

(b)

FIGURE 3: (a) Examples of the inside circulation at midnight $(0 \mathrm{~h})$ and $6 \mathrm{~h}(6 \mathrm{a} . \mathrm{m}$.) with zoom on the orifice entrance. Scale $(\mathrm{m} / \mathrm{s})$ for the vector length: (Grid Units/Magnitude) = 1. (b) Examples of the inside circulation at noon $(12 \mathrm{~h})$ and $18 \mathrm{~h}(6 \mathrm{p} . \mathrm{m}$.) with zoom on the orifice entrance. Scale $(\mathrm{m} / \mathrm{s})$ for the vector length: (Grid Units/Magnitude) $=1$.

Figure 6(b) shows the evolution consequences through the in-time cumulated water quantities over 4 days (ratio between the condensed water and the water vapor quantity contained in the volume at the initial moment). This figure shows also the steady-state effect obtained in 3 days.
Even if low, the condensation phenomenon, however, is not negligible, and its temporal variation starts by condensing at about $7 \mathrm{pm}(19 \mathrm{~h})$, with a first maximum around midnight $(24 \mathrm{~h})$ and an end of the phenomenon (transition from condensation to evaporation) at $6 \mathrm{am}$ the next day $(30 \mathrm{~h})$. This 

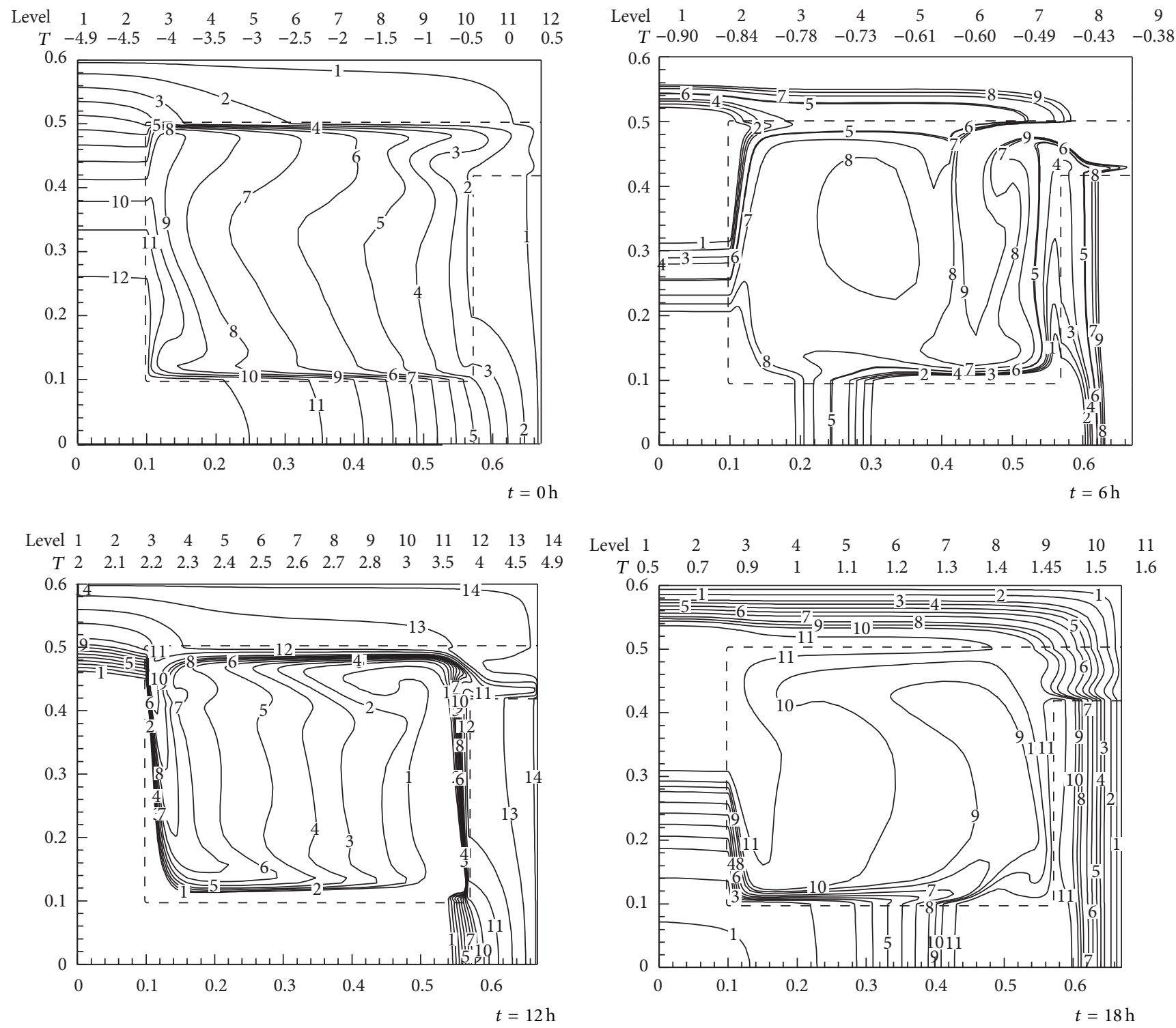

FIGURE 4: Isotherms (difference temperatures from $15^{\circ} \mathrm{C}$ ) evolution inside the structure at various moments. Phase $\varphi=0 \mathrm{~h}: t=0 \mathrm{~h}$ with $T_{\text {ext }}=10^{\circ} \mathrm{C} ; t=6 \mathrm{~h}$ with $T_{\text {ext }}=15^{\circ} \mathrm{C} ; t=12 \mathrm{~h}$ with $T_{\text {ext }}=20^{\circ} \mathrm{C} ; t=18 \mathrm{~h}$ with $T_{\text {ext }}=15^{\circ} \mathrm{C} . T_{\text {ext }}$ is the external temperature.

first step matches with the internal temperature decrease. A second step starts immediately after and ends at 7 am $(31 \mathrm{~h})$ the second day, with a maximum at around 6.30 a.m. This second step, more upper than the first one, matches with a water vapor providing by renewing, that is to say, by hydrometric exchanges between outside and inside of the structure.

These figures show in an amazing way the importance of the thermal hydrometric exchanges with the external medium compared with the pure convective phenomenon inside the structure.

To better quantify the hydrometric exchanges between the outside and inside of the volume at each instant $t_{1}$, we have defined the percentage of condensed water vapor by the following equation as a function of phase, the bottom wall of the structure being assumed remaining dry at each moment:

$$
\eta=\frac{\int_{0}^{t_{1}}\left(q_{e}(t)-q_{s}(t)\right) d t}{\int_{0}^{t_{1}} q_{e}(t) d t} \times 100 \%
$$

In Figure 7 which follows, we can see that the mean level of condensation is situated in a 5\% and 6\% range at the end of the third day and then is stabilized.

3.2. Phase $\varphi=12 \mathrm{~h}$. Now we show the more significant results obtained with a phase $\varphi=12 \mathrm{~h}$ (Figure 8). 

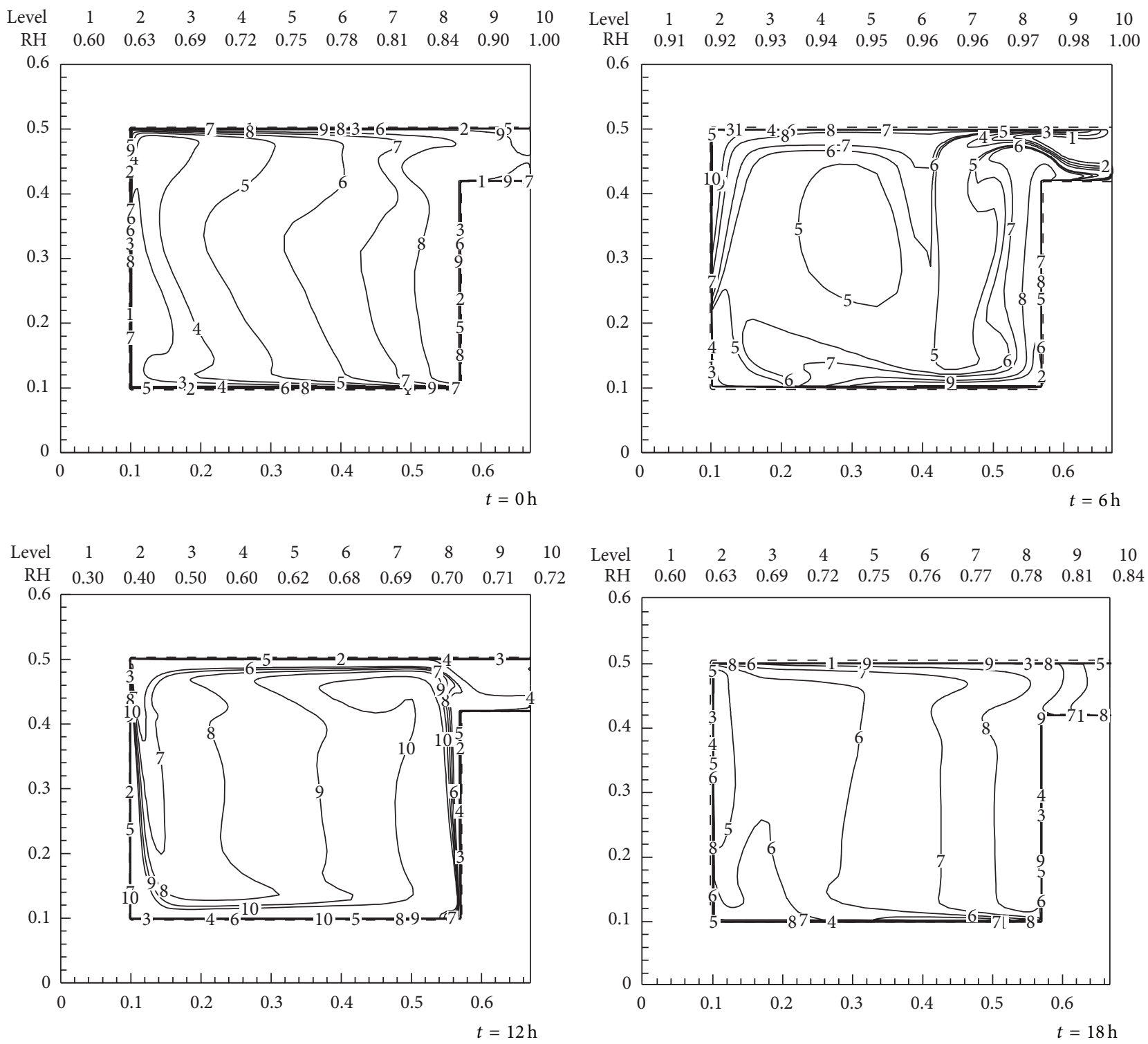

Figure 5: Relative isohumidity evolutions inside the structure at various moments $t$. Phase $\varphi=0 \mathrm{~h}: t=0 \mathrm{~h}$ with $\mathrm{RH}=90 \% ; t=6 \mathrm{~h}$ with $\mathrm{RH}=90 \% ; t=12 \mathrm{~h}$ with $\mathrm{RH}=60 \% ; t=18 \mathrm{~h}, \mathrm{RH}=90 \%$.

A primary observation is that dynamics of the circulation inside the structure are the same, at about some details, at the same times as the ones presented in the previous Figure 3. This demonstrates the main role of the "thermal driving force" on the internal circulation.

The width section of local temperature and relative hygrometry are represented in Figures 9 and 10. Isotherms, gap values from $15^{\circ} \mathrm{C}$ (Figure 9), show convective movements due to temperature steps relatively important in some cases, up to about $5^{\circ} \mathrm{C}$ at $0 \mathrm{~h}$ (midnight) and $3^{\circ} \mathrm{C}$ at noon $(12 \mathrm{~h})$.

Dealing with the relative iso humidity (Figure 10), we can see a humidity concentration relatively high in the vicinity of the orifice and on the walls submitted to the constraints at $6 \mathrm{~h}(\mathrm{am}), 12 \mathrm{~h}$ (noon), and $18 \mathrm{~h}(6 \mathrm{pm})$, where the external relative hygrometry is the highest $(90 \%)$. That causes an internal condensation all along the walls, essentially at $6 \mathrm{~h}$ (am).
The hygrometry dispatch remains relatively homogeneous out of these zones.

It also appears that the diffusion effect of the water vapor inside the structure has more important kinetics than the convection one and more actively participates in the humidity homogenisation.

As for the phase $\varphi=0 \mathrm{~h}$, starting from the synchronized boundary conditions, that is to say, coincidence between maxima and minima of temperature and relative hygrometry ( $\varphi=12 \mathrm{~h}$, Figure 8 ), we can see, in Figure 11(a), that the temperature and hygrometry mean values have a similar behaviour to the one at the outside of the structure. However, we can note a phase displacement of about 2 hours time between $T$ and $\mathrm{RH}$ essentially depending on the nature of the walls of the structure.

The time during which mean internal $\mathrm{RH}>90 \%$ is identical to the external hydrometric constraint when this one is 


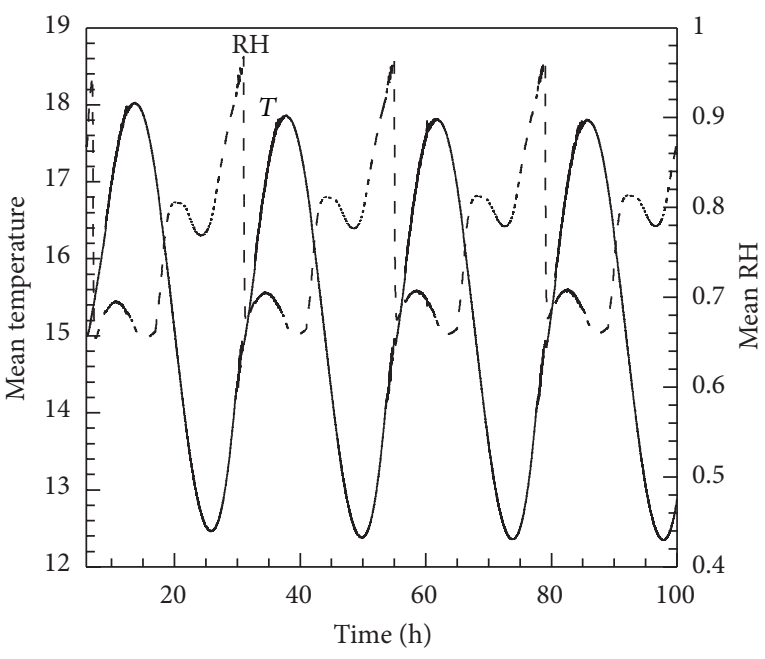

(a)

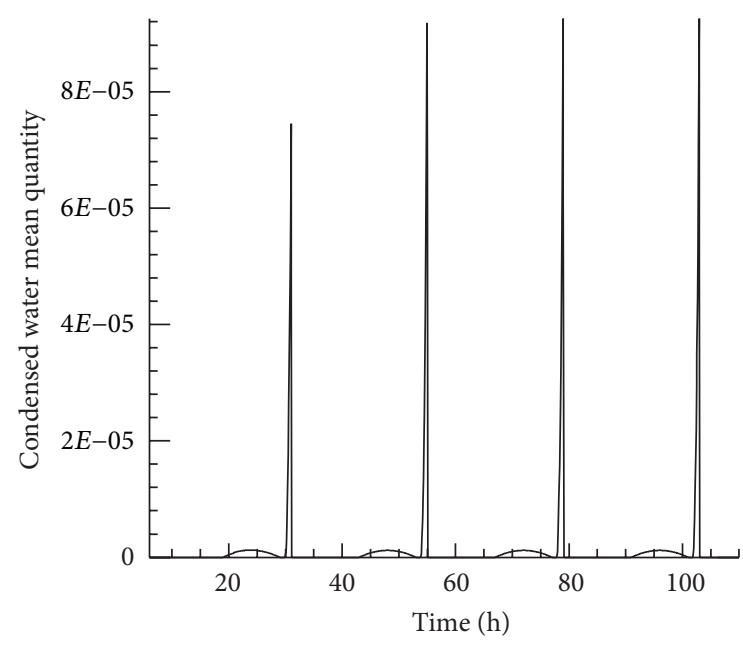

(b)

Figure 6: (a) Mean temperature and relative humidity evolutions of the inner air. (b) Evolutions of the mean quantity of condensed water vapour inside the structure.

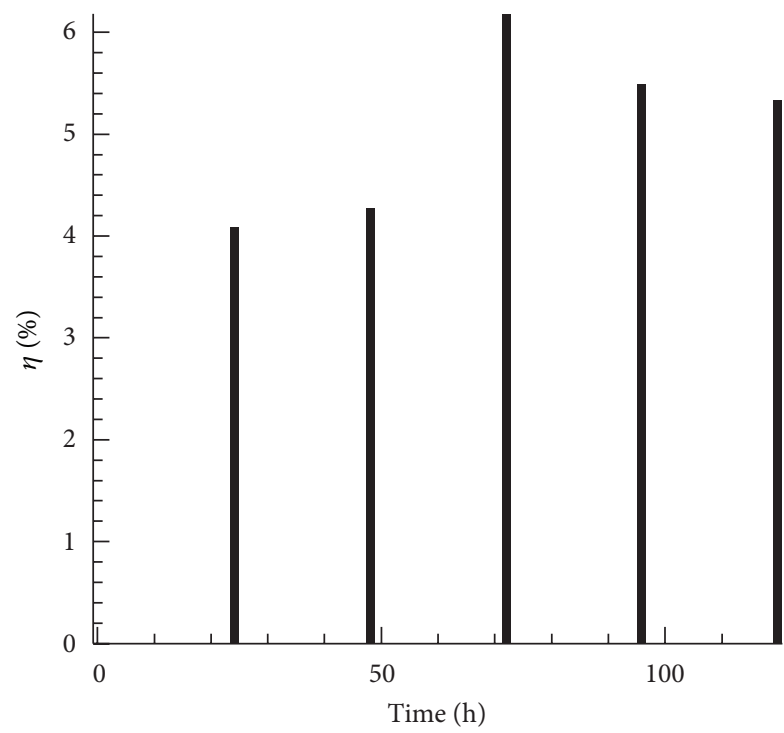

Figure 7: Day after day evolution of the condensed water vapour ratio. Phase $\varphi=0 \mathrm{~h}$.

equal to $90 \%$. But there are some times during which internal $\mathrm{RH}$ is lower than $60 \%$ pointing out drying periods of the air inside the volume. This fact can be particularly observed at $0 \mathrm{~h}$ (midnight), when the imposed outside relative hygrometry is equal to $60 \%$, but when the internal gap of temperature is positive in comparison with external ones.

The spatio temporal evolutions of the relative humidity (Figure 10) lead to hold in time water quantities, that is to say, ratio between the condensed water vapor quantity and the water vapor contained in the air inside the volume at the initial time. In Figure 11(b) showing the condensed water evolutions over 4 days, we can again observe the stabilization effect of the process in about 3 days. The temporal variation

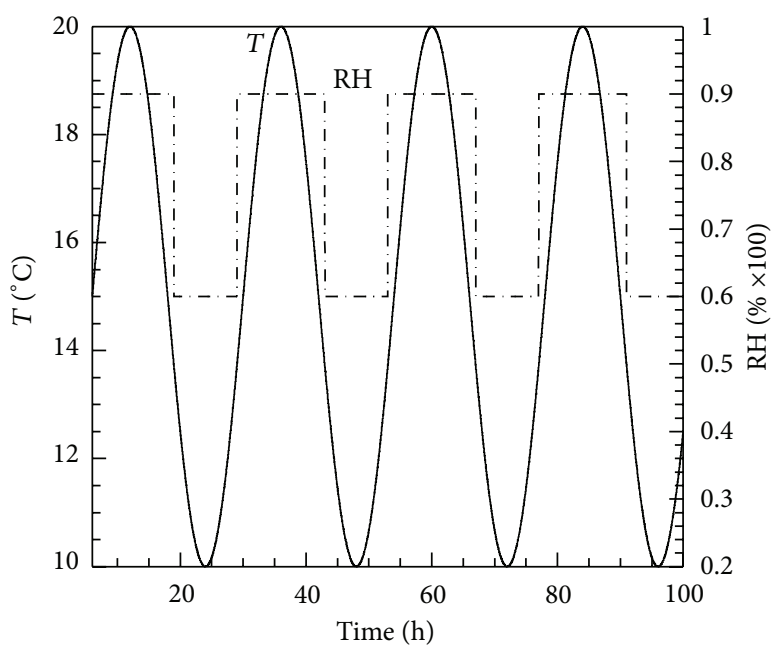

FIgURE 8: Phase $\varphi=12 \mathrm{~h}$. Temperature and relative humidity evolutions of the external air applied to the constrained walls (boundary conditions of the model).

of the condensation starts at $7 \mathrm{~h}(\mathrm{am})$, reaches a maximum

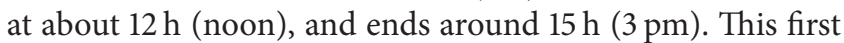
condensation step is linked with a water vapor renewing, that is to say, with the external-internal hydrometric exchanges through the orifice of the structure, and could be used to recover some atmospheric water. The amplitude of the phenomenon is about 10 times upper than the one observed in the case of $\varphi=0 \mathrm{~h}$.

We must point out a second condensation step which starts at $19 \mathrm{~h}(7 \mathrm{pm})$ and ends at $5 \mathrm{am}$ the next day $(29 \mathrm{~h})$ with a maximum at about $1 \mathrm{~h} 30$ the following day. This second step, lower than the first one, cannot be seen on the figure because of its very small amplitude. It corresponds with an internal falling temperature. We can still verify the importance of the 

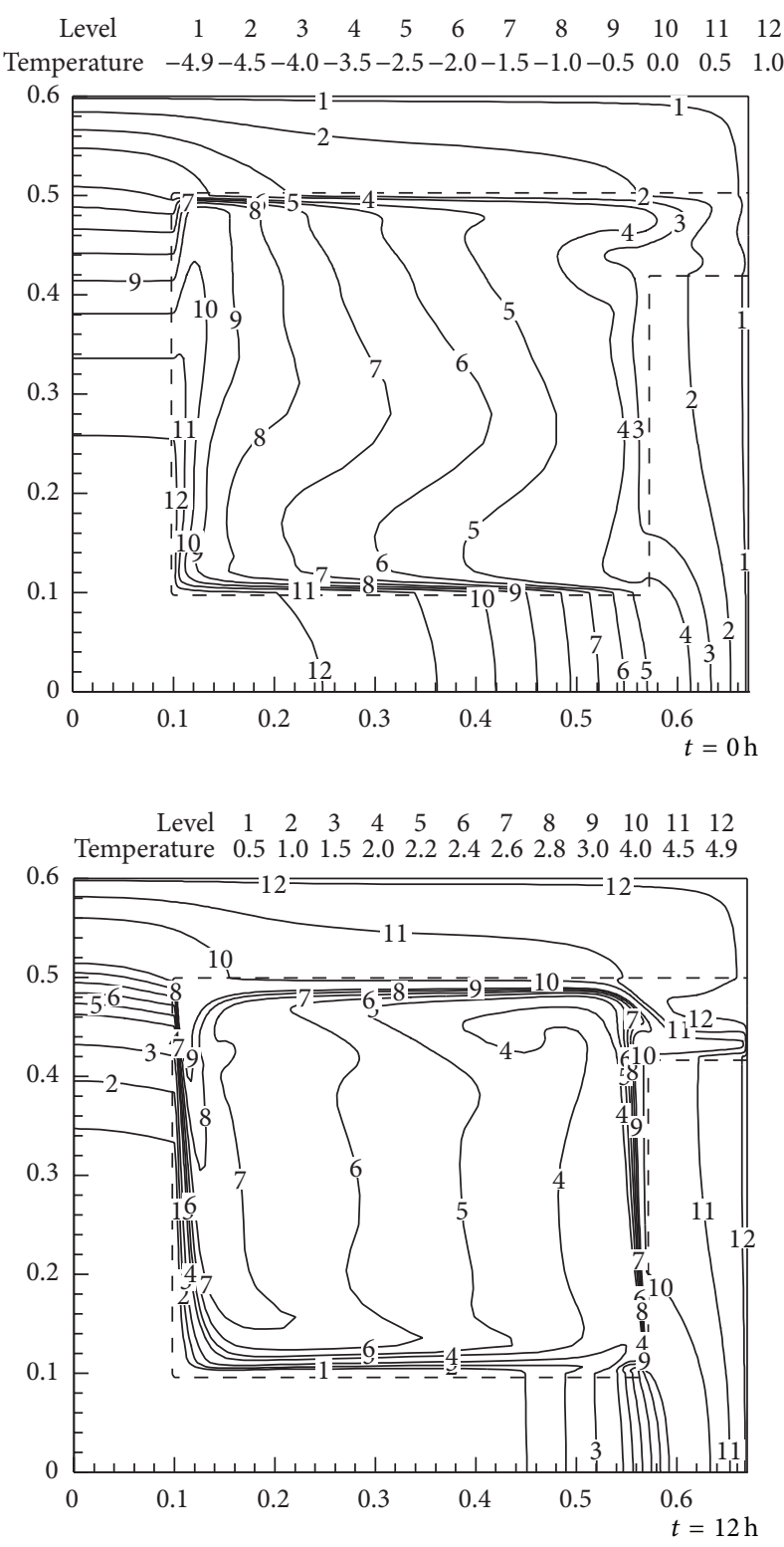

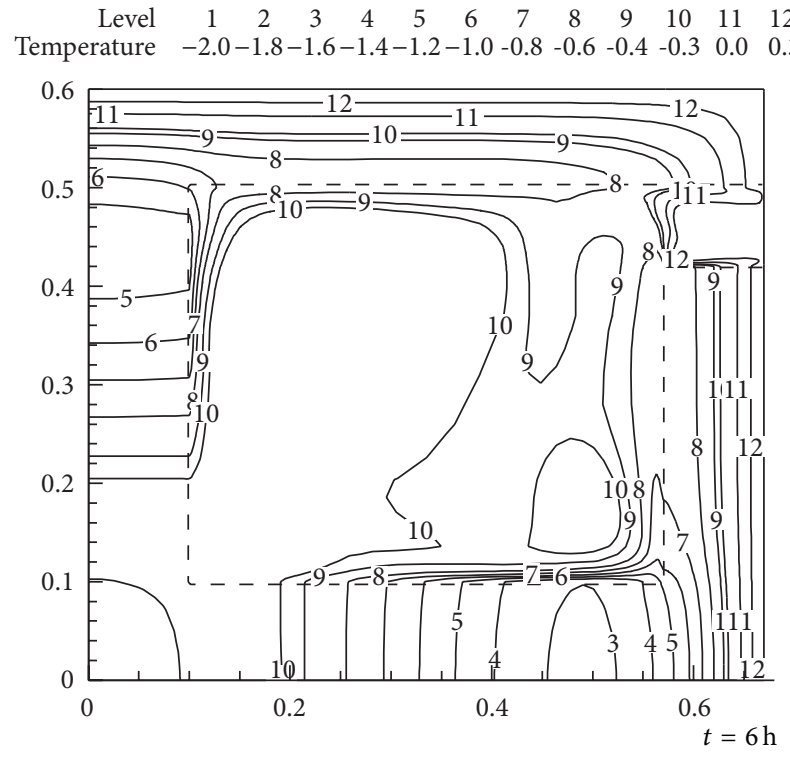

$\begin{array}{lllllllllllll}\text { Level } & 1 & 2 & 3 & 4 & 5 & 6 & 7 & 8 & 9 & 10 & 11 & 12\end{array}$ $\begin{array}{llllllllllllll}\text { Temperature } & 0.5 & 0.8 & 1.0 & 1.2 & 1.4 & 1.5 & 1.6 & 1.7 & 1.8 & 2.0 & 2.5 & 2.8\end{array}$

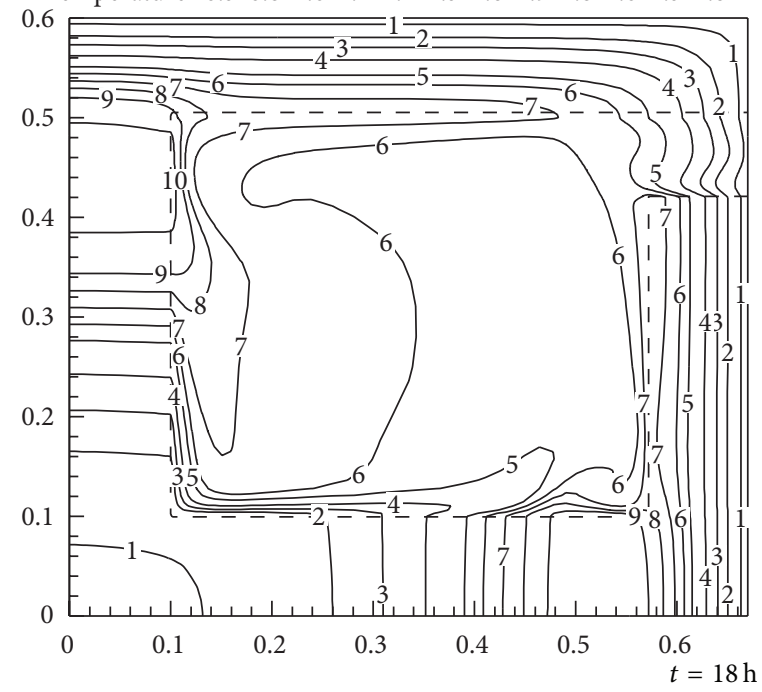

FIgURE 9: Isotherms (difference temperatures from $15^{\circ} \mathrm{C}$ ) evolution inside the structure at various moments.

thermal and hydrometric exchanges with the outside medium compared to the pure convective phenomenon inside the structure.

By comparing Figures 6 and 11 we can point out the various possibilities resulting from the phase between external temperature and hygrometry.

The mean condensation level (Figure 12) takes place above $12 \%$ at the end of the third day and then is stabilized. By comparing Figure 12 with Figure $7(\varphi=0$ h) it can be seen that the efficiency is 2 times higher, which demonstrates the important role of the phase between $T$ and $\mathrm{RH}$.

As in the case of $\varphi=0 \mathrm{~h}$, the previous curves have permitted to display the mass and thermal dynamics of the air at each moment inside the structure. All the same numerical integration of the variables in the space, the evaporationcondensation phenomena were displayed and quantified.

\section{Conclusion/Prospects}

We have studied the influence of parameters such as the thermal and hydrometric external boundary conditions and the phase between temperature and hygrometry on the condensed water vapor quantities, in a fixed parallelepiped structure the wall thickness of which and nature (marble) and the orifice dimension are fixed. We have assumed that the inside bottom wall remains dry all along the computation. The influence of the other parameters such as the residence time of the water vapor inside the structure, depending on the 

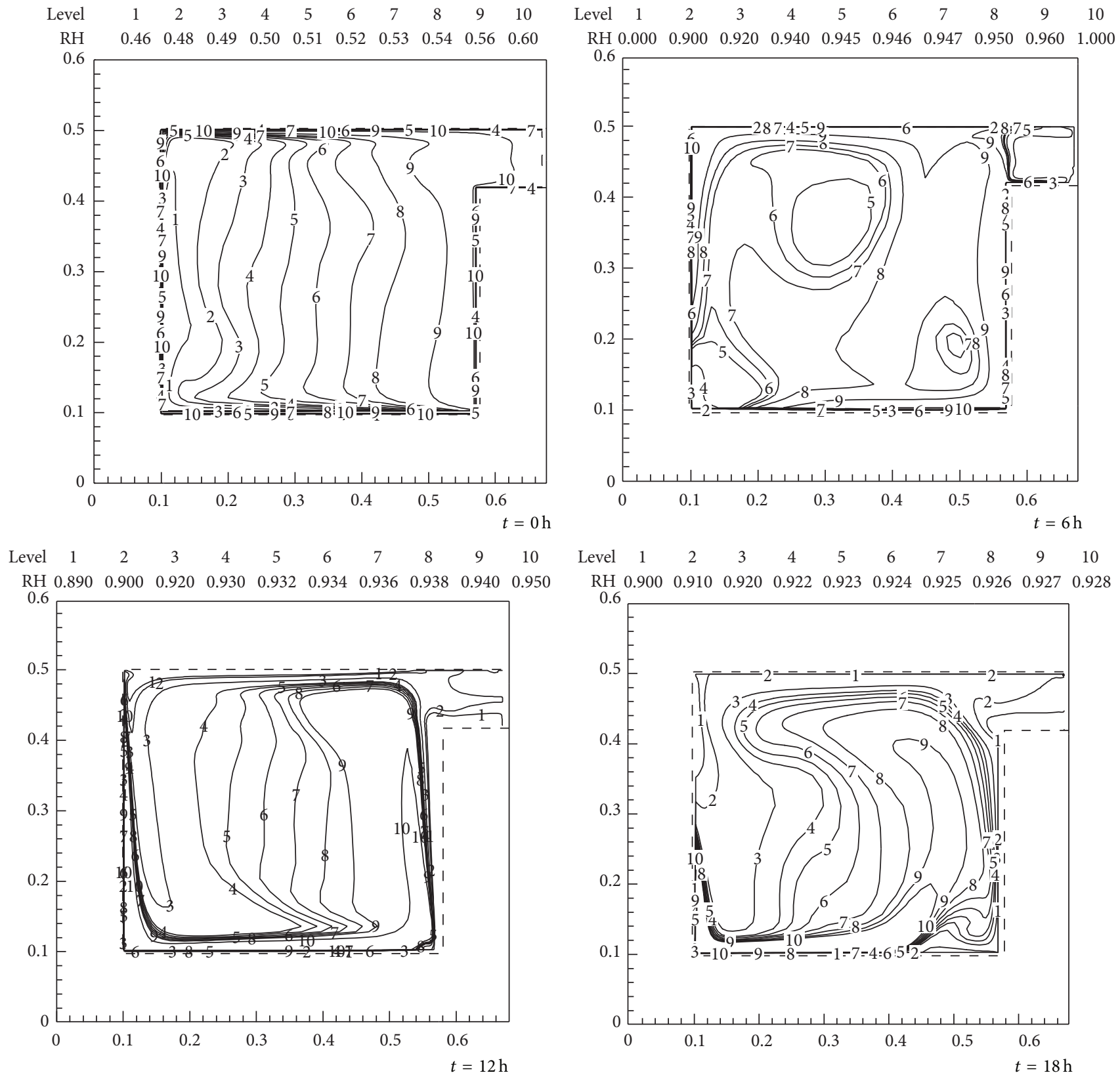

$\begin{array}{lllllllllll}\text { Level } & 1 & 2 & 3 & 4 & 5 & 6 & 7 & 8 & 9 & 10\end{array}$

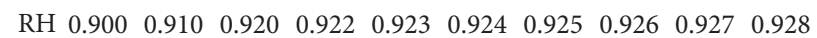

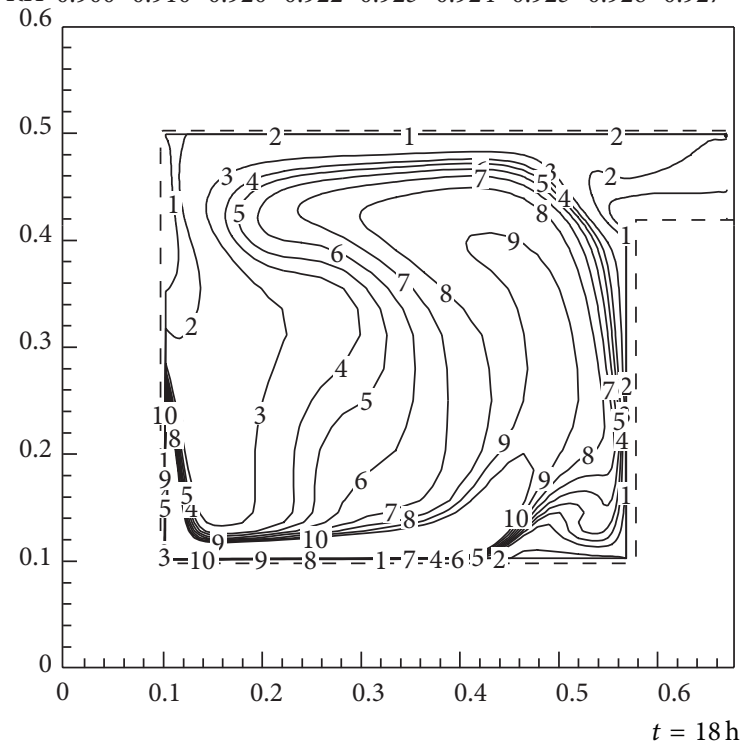

FIGURE 10: Relative isohumidity evolutions inside the structure at various moments. Phase $\varphi=12 \mathrm{~h} t=0 \mathrm{~h}$ (midnight) with RH $=60 \%$; $t=6 \mathrm{~h}(\mathrm{am})$ with $\mathrm{RH}=90 \% ; t=12 \mathrm{~h}$ with $\mathrm{RH}=90 \% ; t=18 \mathrm{~h}$ with $\mathrm{RH}=90 \%$.

orifice dimension and the longitudinal or transversal section, nature and thickness of the walls, and the presence or not of a thin layer of water on the inside bottom wall, and so on, will be the aim of other publications.

The present study points out an important dependency on the condensed water vapor quantities as a function of the considered parameters. We have noted, for the width section only, that the more significant parameter is the phase between temperature and hygrometry. The external-internal temperature gap acts as a "thermal driving force" on the internal circulation and the renewing of the water vapor inside the structure.
In Figure 13, we can see that the condensed water vapor quantities are very depending on the phase $\varphi(T / R H)$ and reach a maximal value when $\varphi$ is about $15 \mathrm{~h}$.

The actual running computations using other conditions as length section and variable orifice size, acting on the residence time and renewing of the water vapor inside the volume, equally show the existence of condensed water vapor maximal values depending on the fixed conditions Batina et al. [8]. One of these studies taking into consideration the inside bottom wall covered by a thin layer of water remaining at a constant level will be presented in a future paper. 


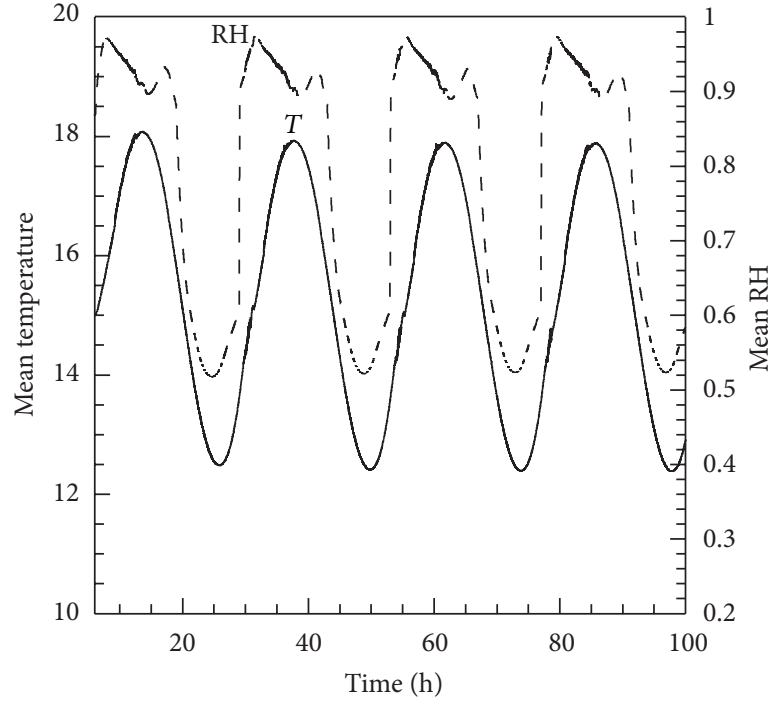

(a)

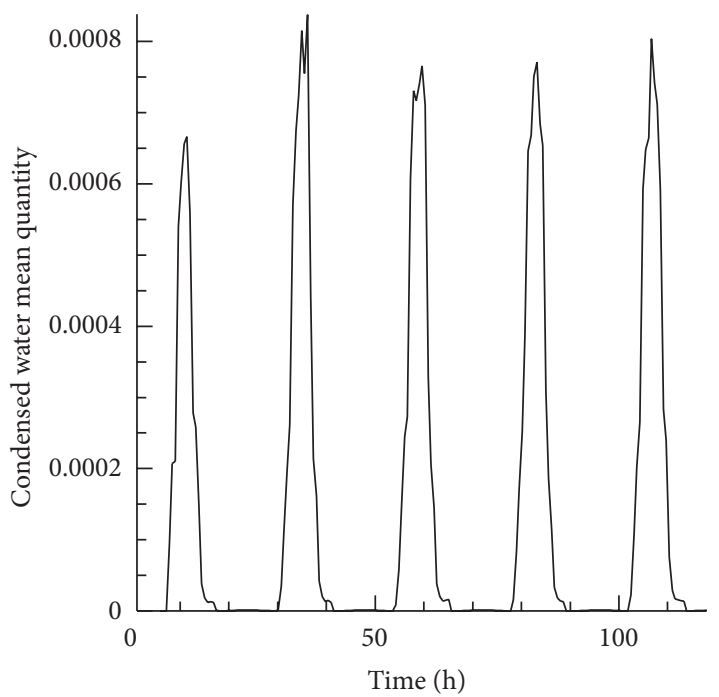

(b)

FIGURE 11: (a) Mean temperature and relative hygrometry of the internal air. (b) Mean condensed water vapour evolution inside the structure over four days.

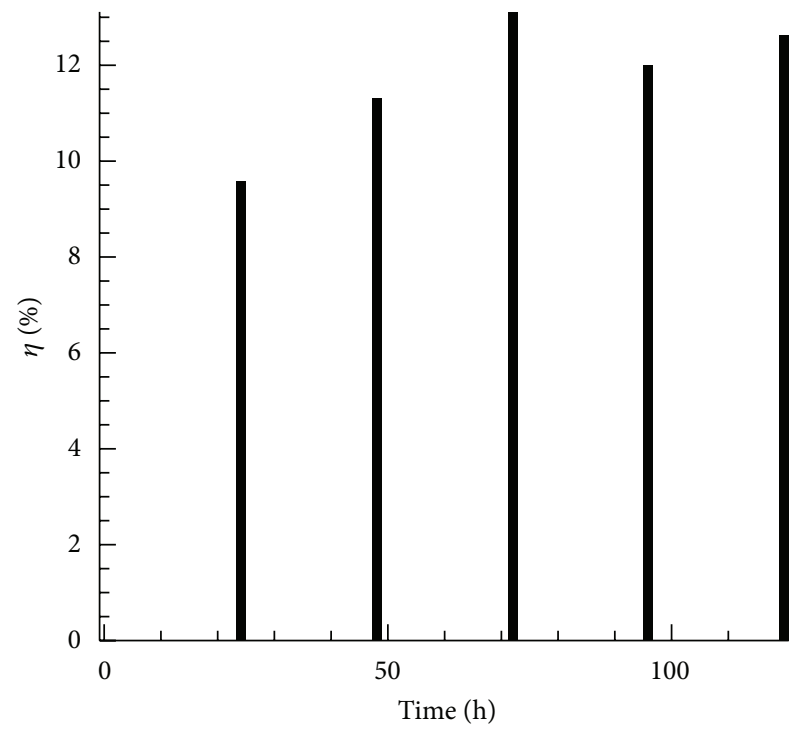

FIGURE 12: Day after day evolution of the condensed water vapour ratio. Phase $\varphi=12 \mathrm{~h}$.

The systematic study of the influence of all these parameters and the results already obtained open some new promising prospects able to enhance the condensation phenomena inside this type of structure.

In a near future, the software offers numerous possibilities whose results concern water recovery inside partly closed structure where very high humidity can take place (maturing cellars, mushroom beds, etc.). This software will permit to determine a better hygrometry control system and improvement ways.

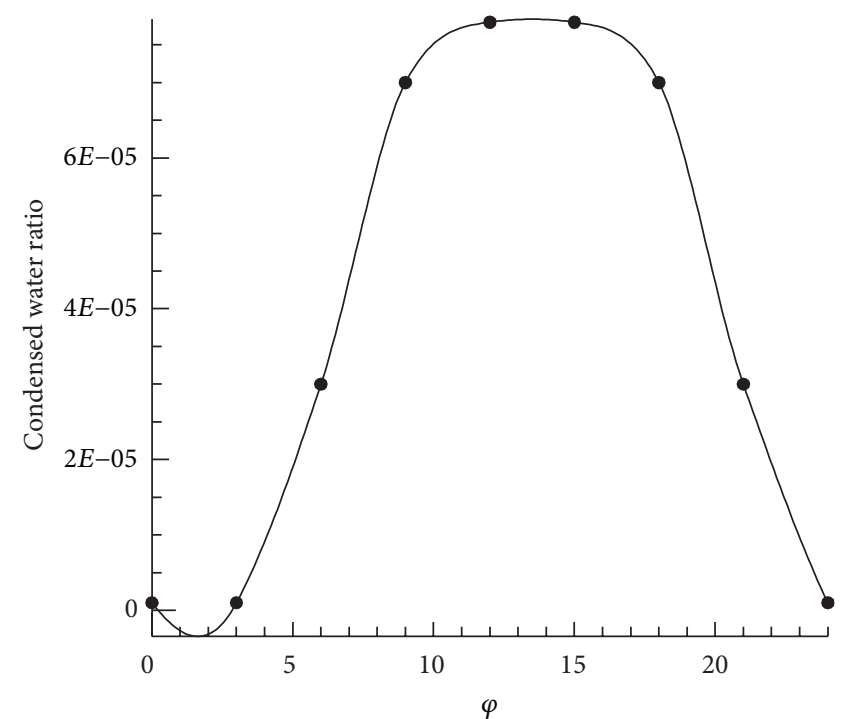

FIgURE 13: Ratio of condensed water vapour as a function of the phase $(T / \mathrm{RH})$ for an $8 \mathrm{~cm}$ orifice.

\section{Nomenclature and Units}

C: Vapor concentration

$c_{p}:$ Heat capacity, $\mathrm{J}^{\mathrm{kg}} \mathrm{kg}^{-1} \cdot \mathrm{K}^{-1}$

D: Mass diffusivity, $\mathrm{m}^{2} \cdot \mathrm{s}^{-1}$

$g$ : Gravitational acceleration, $\mathrm{m} \cdot \mathrm{s}^{-2}$

La: Latent heat, ${\mathrm{J} \cdot \mathrm{kg}^{-1}}^{-1}$

$p$ : Pressure, $\mathrm{Pa}$

$q_{e}:$ Entering quantity of water vapor, $\mathrm{kg}$

$q_{s}$ : Outgoing quantity of water vapor, $\mathrm{kg}$ 
RH: $\quad$ Relative Humidity, in \%

$t: \quad$ Time, $s$

T: $\quad$ Temperature, $\mathrm{K}$

$T_{\text {ext }}$ : $\quad$ External temperature, $\mathrm{K}$

$\vec{V}=(u, v):$ Speed field, $\mathrm{m} \cdot \mathrm{s}^{-1}$.

\section{Greek Symbols}

$\delta T$ : Temperature difference from $15^{\circ} \mathrm{C}$ ( 0 initial value), $\mathrm{K}$

$\varphi$ : $\quad$ Phase between $T$ and

$\rho$ : Volumic mass, $\mathrm{kg} \cdot \mathrm{m}^{-3}$

$\mu$ : Dynamic viscosity, Pa.s

$\lambda: \quad$ Thermal conductivity, $\mathrm{W} \cdot \mathrm{m}^{-1} \cdot \mathrm{K}^{-1}$

$\eta$ : Condensed water ratio.

\section{Acknowledgment}

The authors thank Mr. Stéphane Glockner of the TREFLE Laboratory - UMR 8508, for his assistance in using the finite volumes method.

\section{References}

[1] V. S. Nikolayev, D. Beysens, A. Gioda, I. Milimouk, E. Katiushin, and J.-P. Morel, "Water recovery from dew," Journal of Hydrology, vol. 182, no. 1-4, pp. 19-35, 1996.

[2] M. Muselli, D. Beysens, J. Marcillat, I. Milimouk, T. Nilsson, and A. Louche, "Dew water collector for potable water in Ajaccio (Corsica Island, France)," Atmospheric Research, vol. 64, no. 14, pp. 297-312, 2002.

[3] D. Beysens, I. Milimouk, V. S. Nikolayev et al., "Comment on "The moisture from the air as water resource in arid region: hopes, doubt and facts" by Kogan and Trahtman," Journal of Arid Environments, vol. 67, no. 2, pp. 343-352, 2006.

[4] P. Gandhidasan and H. I. Abualhamayel, "Modeling and testing of a dew collection system," Desalination, vol. 180, no. 1-3, pp. 47-51, 2005.

[5] D. Beysens, M. Muselli, V. Nikolayev, R. Narhe, and I. Milimouk, "Measurement and modelling of dew in island, coastal and alpine areas," Atmospheric Research, vol. 73, no. 1-2, pp. 1-22, 2005.

[6] J. P. Caltagirone and J. Breil, "A vector projection method for solving the Navier-Stokes equations," Comptes Rendus de l'Académie des Sciences-Séries IIB-Mechanics-Physics-Astronomy, vol. 327, no. 11, pp. 1179-1184, 1999.

[7] J. Batina, R. Peyrous, and J. Castaing-Lasvinottes, "Condensation de vapeur d'eau en milieu partiellement clos soumis à des conditions périodiques de température et d'humidité : simulationet influence des conditions opératoires," in Proceedings of the Society for Theriogenology (SFT) Congress, pp. 345-350, Toulouse, France, June 2008.

[8] J. Batina, R. Peyrous, and J. Castaing-Lasvinottes, "Conditions opératoires optimales favorisant la condensation de vapeur d'eau en milieu partiellement clos soumis à des variations de température et d'humidité," in Proceedings of the JITH Congress, pp. 345-350, Djerba, Tunisia, March 2009.

[9] D. Beysens, M. Muselli, J.-P. Ferrari, and A. Junca, "Water production in an ancient sarcophagus at Arles-sur-Tech (France)," Atmospheric Research, vol. 57, no. 3, pp. 201-212, 2001.
[10] G. Perard and C. Leborgne, "Sarcophage d'Arles-sur-Tech, rapport technique,” Houille Blanche, vol. 6, pp. 873-881, 1961. 

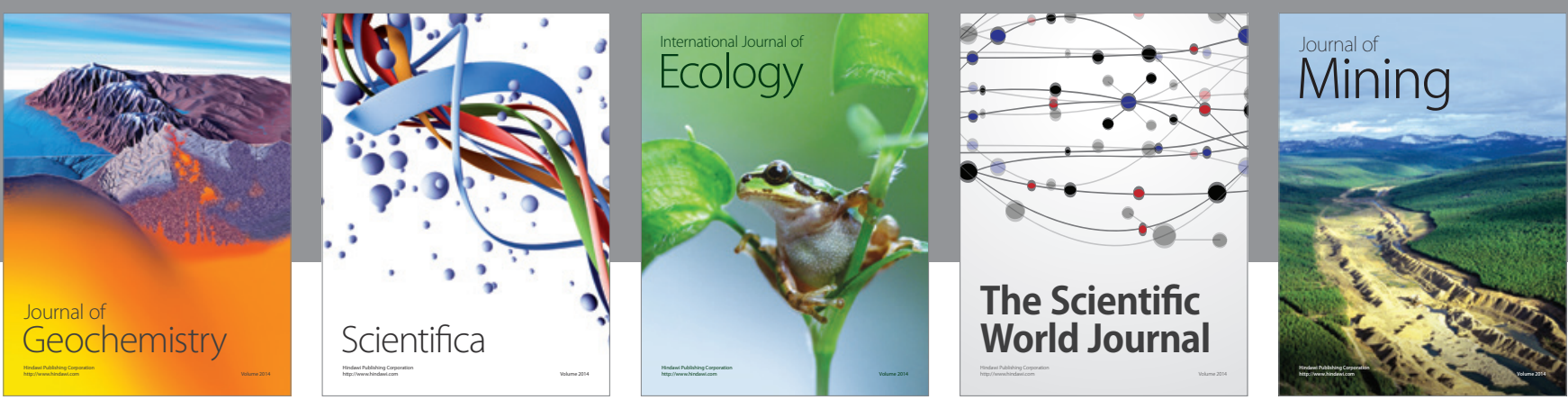

The Scientific World Journal
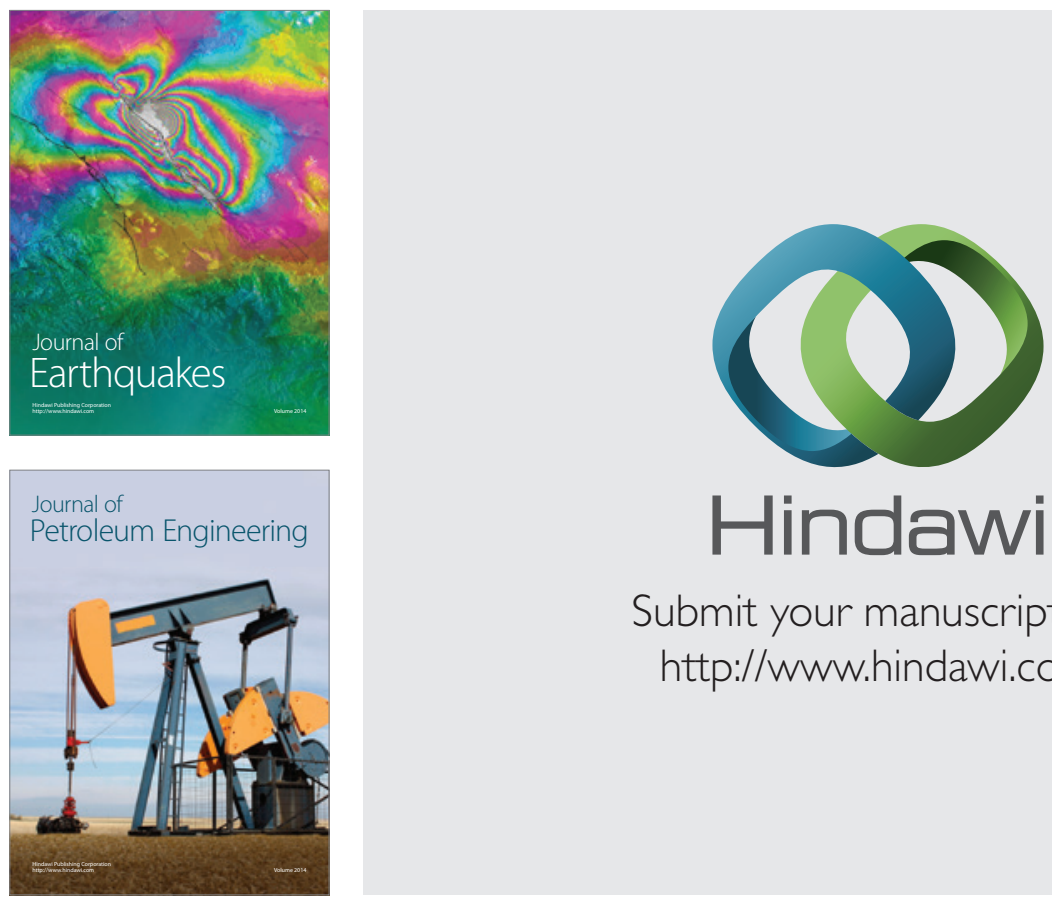

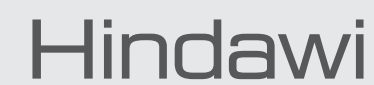

Submit your manuscripts at

http://www.hindawi.com
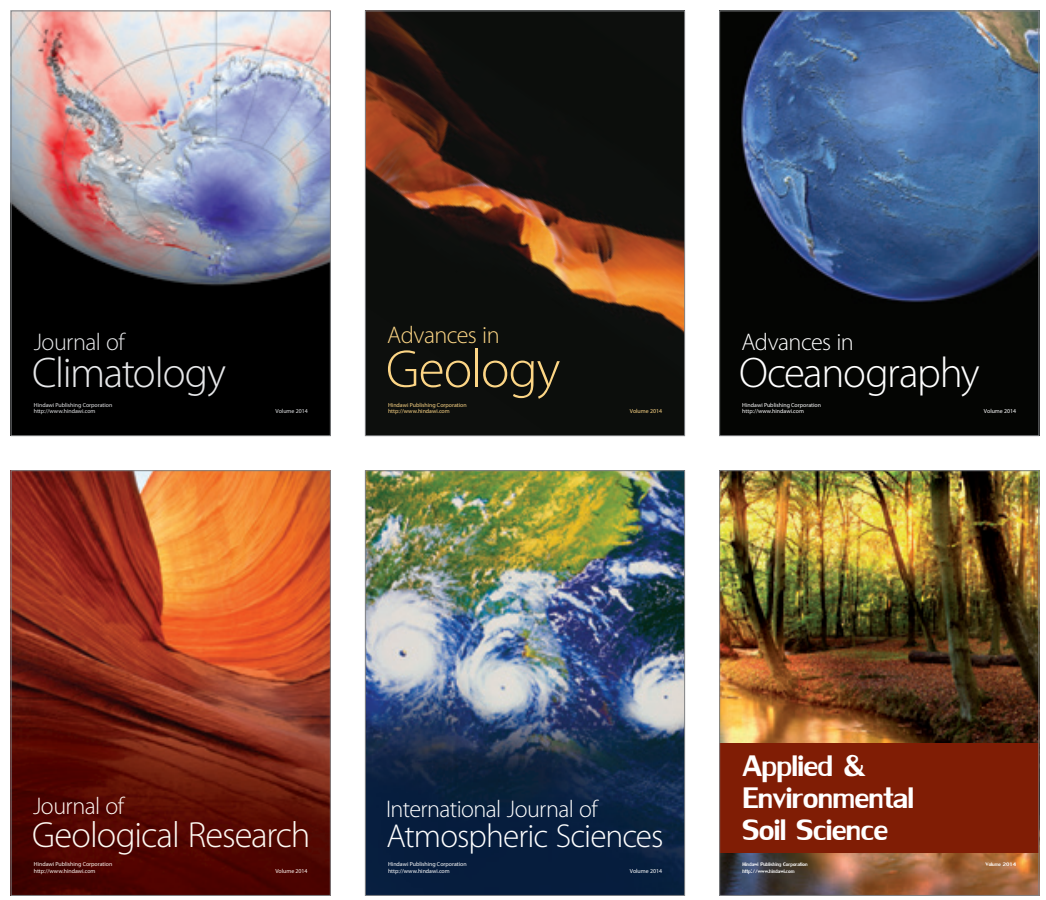
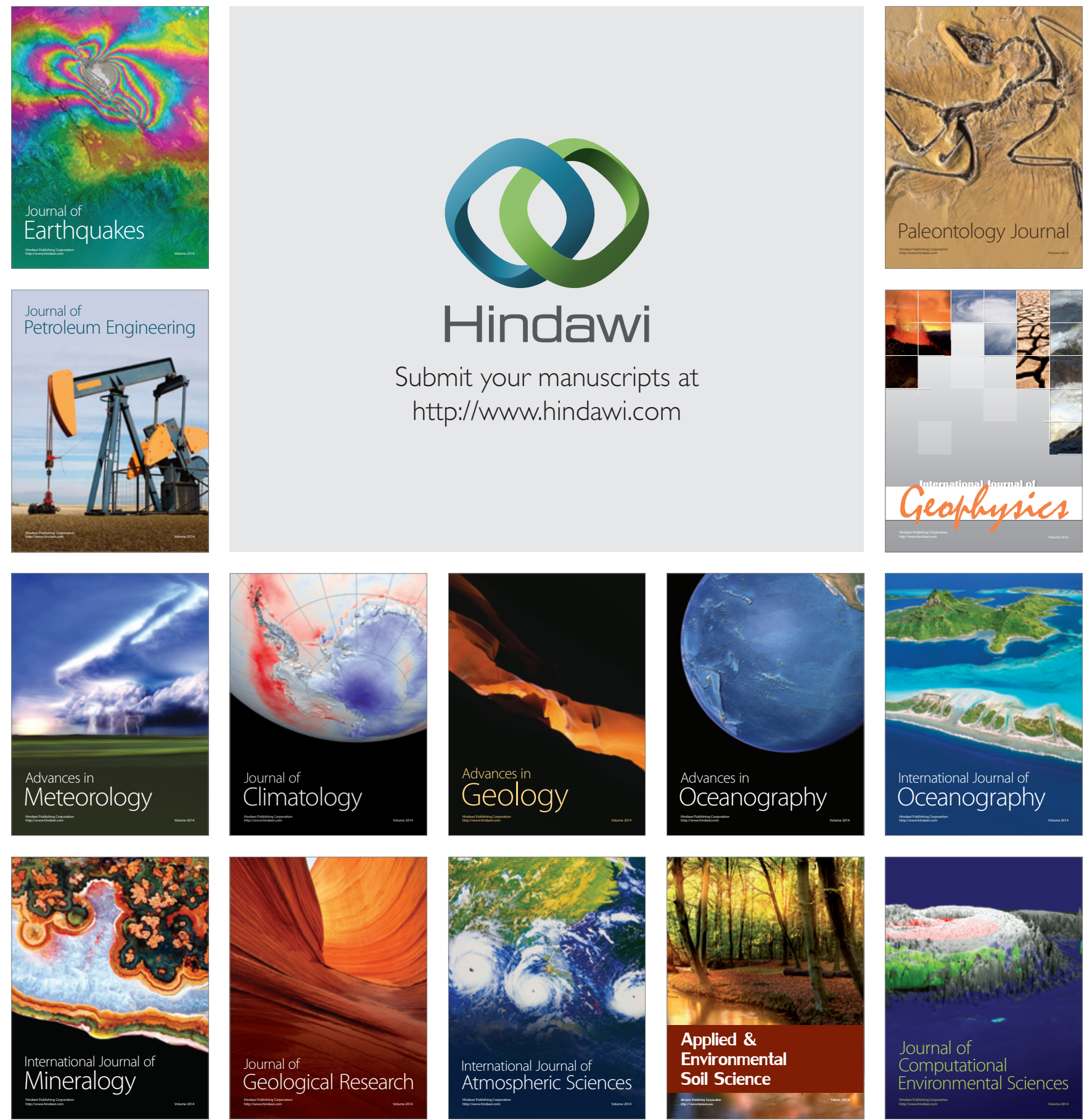